\title{
A BAYESIAN GAME FOR A PROFIT AND LOSS SHARING CONTRACT
}

\author{
Djaffar Lessy ${ }^{1}$, Marc Diener ${ }^{2}$ and Francine Diener ${ }^{3}$ \\ ${ }^{1}$ Université Côte d'Azur, IAIN Ambon, France and Indonesia, djefles79@yahoo.com \\ ${ }^{2}$ Université Côte d'Azur, France, marc.diener@unice.fr \\ ${ }^{3}$ Université Côte d'Azur, France, francine.diener@unice.fr
}

\begin{abstract}
This paper presents a Bayesian game model for a profit-and-loss sharing (PLS) contract. We develop the model in two parts, one for a non-social bank and the other for a social bank. The model is proposed to reduce the adverse selection problem inherent in PLS contracts. The game starts with incomplete information; Islamic banks do not know exactly what type of agent is applying for a PLS contract, and whether the agents are efficient or non-efficient. We assume that the banks assign the agent type to a prior probability. Determination of the profit-sharing ratio of the contract is then discussed, and we look for the Bayesian Nash equilibrium as a solution or outcome of the game. We show that banks offer interesting but risky contracts to agents if they assign high probability to the agents being efficient. In contrast, they offer less risky contracts if they assign high probability to the agents being non-efficient. The results can be considered by Islamic banks to reduce the adverse selection problem in PLS contracts.
\end{abstract}

Keywords: Bayesian game, Profit and loss sharing, Adverse selection, Islamic finance. JEL classification: C02; C7; D82; E51; G21.

Article history:

Received : October 8, 2020

Revised : March 9, 2021

Accepted : : May 27, 2021

Available online : August 31, 2021

https://doi.org/10.21098/jimf.v7i3.1367 


\section{INTRODUCTION}

\subsection{Background}

Profit and loss sharing (PLS) (especially mudarabah) contracts are made between two parties, an investor (a bank/rabb-ul-mal) and a client (a borrower/mudarib). The investor provides the capital and the clients provide their skills and expertise in managing and conducting their business. Any profit is shared between the two parties according to a previously agreed ratio (the profit-sharing ratio). However, in the event of a loss, investors will lose all or part of their capital together with the time and effort invested in the project.

A PLS contract involves high risk due to adverse selection and moral hazard problems. According to Lessy, Koudjeti, Diener, and Diener (2019), the risk associated with such a contract can occur at the time of the contract being agreed or during the contract period. In the related literature, several studies have considered the problems related to PLS contracts. Tag El-Din (2008), for instance, shows a negative relationship between the profit-sharing and risk ratios in an optimal PLS contract. He further points out that the optimal profit-sharing ratio of PLS contracts depends on the risk-attitude differential of Islamic banks and entrepreneurs. Kamarudin and Ismail (2013) note that Islamic banks can maximise the profit and provide an incentive to borrowers (entrepreneurs) in such contracts, if the expected profit for the banks is higher than the return. Ouidad (2013) also proposes a model for the provision of incentives to entrepreneurs by Islamic banks in PLS contracts. Sapuan (2016) states that this type of contract is becoming less preferable because of information asymmetry and consequently the presence of adverse section and moral hazard problems. Apart from these studies, several other works discuss PLS contracts, including those of Fakir and Tkiouat (2016), Jouaber and Mehri (2017), Ajmi, Aziz, Kassim, and Mansour (2019), and Lessy et al. (2019). We will describe these studies in more detail in section 2.2.

In this paper, we propose a mathematical model of the PLS contract using a Bayesian game, in which we determine the Bayesian Nash equilibrium as the outcome of the game. Considering the game-theoretic framework, our model demonstrates that Islamic banks can reduce the adverse selection inherent in PLS contracts. This can occur because of the asymmetric information between the bank and the agent. The Islamic bank does not fully know if the agent requesting credit is efficient or non-efficient. This lack of information can result in adverse selection when offering a contract, as one of the parties is as at disadvantage.

A Bayesian game starts with incomplete information which, in this case, pertains to the agent party to PLS contract. In the game, the bank assigns a type (efficient or non-efficient) to the agent which has a certain probability. The determination of this probability is important, as it influences the decision whether to offer a PLS contract or not.

In our model, we propose that the bank has two different contracts: a risky one, with a high profit-sharing agent ratio; and a less risky one, with a low profit-sharing ratio. According to Shaikh (2011), considering the risks of a business project, an Islamic financial contract demands a high profit-sharing ratio, resulting in agents' low motivation and efforts as their return is low. In addition, Ouidad (2013) suggests a high profit-sharing ratio in a PLS (mudarabah) contract if the project is of high risk, but a low one if the project is of low risk. We base the construction of our model on these two studies. 
The bank will offer one of the two types of contract, and then the agent will decide whether to accept or refuse it. The profit-sharing ratio is different for the two contracts. Therefore, determining the profit-sharing ratio can be a mechanism to avoid adverse selection.

The model is divided into two parts, namely one for a non-social bank and one for a social. A social bank is one with a social purpose, while a non-social bank is one with a profit objective.

\subsection{Objective}

The paper formulates a Bayesian game model as a solution to the adverse selection problem in PLS contracts. The results of the game, which is based on the Bayesian Nash equilibrium, can be considered by Islamic banks in making decisions related to PLS contracts and reducing the adverse selection problem.

The paper is organised as follows. Section II presents the literature review, while Section III presents the Bayesian game model of PLS contracts in non-social and social banks. In section IV, we provide and discuss the results of the game. Finally, section $\mathrm{V}$ concludes the paper and makes recommendations for future research.

\section{LITERATURE REVIEW}

\subsection{Background Theory}

The PLS contract referred to in this paper is an Islamic financial product, namely mudarabah. The PLS contract is a contract between two parties: an investor (rabb-ulmal), who gives money to an agent (borrower/mudarib) to invest in a business. The investor provides the capital and the agent provides their specialised knowledge and work in undertaking the project. The profit from the business (if any) is shared between the two parties according to a previously agreed ratio (profit-sharing ratio), but in the case of loss, the investor will lose all or part of their capital and the agent will have wasted the time and effort devoted to the project, as long as there is no negligence from the agents. ${ }^{1}$ This definition is illustrated in Figure 1.

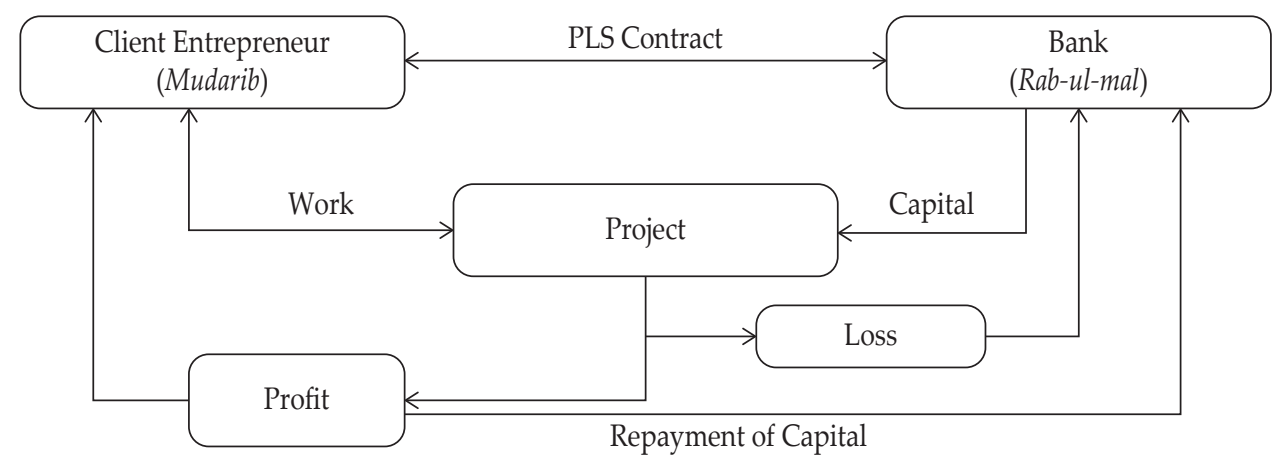

Figure 1.

Schematic of the PLS Contract Mechanism

1 This definition of the PLS contract is based on the previous definitions of Causse-Broquet (2009) and Gait and Worthington (2009). 
We used a Bayesian game to build the model. A definition of a Bayesian game is provided by Koçkesen and Ok (2007) and a definition of the Bayesian Nash equilibrium by Fudenberg and Tirole (1991) which we present below.

\section{Definition 1:}

A Bayesian game is a strategic form game with incomplete information. It consists of:

- $\quad$ a set of players, $N=\{1, . ., n\}$ for each $i \in N$.

- $\quad$ an action set, $S_{i^{\prime}}\left(S=\times_{i \in N} S_{i}\right)$ for each $i \in N$.

- a set of type, $\theta_{i^{\prime}}\left(\theta=\times_{i \in N} \theta_{i}\right)$ for each $i \in N$.

- a probability function, $p_{i}: \Theta_{i} \rightarrow \Delta\left(\theta_{-i}\right)$ for each $i \in N$.

- a payoff function, $u_{i}: S_{i} \times \theta \rightarrow R$ for each $i \in N$.

\section{Definition 2:}

The equilibrium known as the Bayesian Nash equilibrium in a Bayesian game is a Nash equilibrium of the "expanded game", in which each player i's space of pure strategies is the set $S_{i}^{\Theta_{i}}$ of maps from $\theta_{i}$ to $S_{i}$.

The definition of non-social and social banks according to Benedikter (2011) is that a social bank is a bank with a social purpose. It cares about profit, but is oriented towards investing in the community and providing opportunities for disadvantaged people. A non-social bank is a bank that only focuses on profit maximisation.

Weber (2014) gives several examples of social banks, including the Alternative Bank Switzerland, Affinity Credit Union, Clean Energy Development Bank, and New Resource Bank.

We define adverse selection by adapting the definition of Hayes (2020). Adverse selection refers generally to a situation in which agents have information that banks do not have about certain aspects of agent quality. In other words, it is a case in which asymmetric information is exploited. Such information occurs when one party to a transaction has greater material knowledge than the other.

\subsection{Previous Studies}

In his seminal article, Akerlof (1970) modelled adverse selection problems in the used car market, in which the buyer (a car dealer) has less information than the seller. That is, the buyer does not know whether or not it is a good car, and as a result may end up with a car of poor quality but purchased at a high price.

Stiglitz and Weiss (1981) focus on adverse selection in the credit market. The objective of their research is to show that in equilibrium, due to information asymmetry, the credit market can be characterised by credit rationing. With imperfect information, banks must use various screening devices, which can be costly. As a result, they provide loans at high interest rates to borrowers, who have a low likelihood of repaying them. On the other hand, borrowers with a high probability of repaying the loan enjoy a low interest rate. 
It is generally noted that adverse selection is a problem in PLS contracts. Jouaber and Mehri (2017) developed a model based on this problem, which was built to avoid such adverse selection. Their model defines the profit-sharing ratio as a screening device to avoid adverse selection. Formulating the problem mathematically, they show that the high-type agent ${ }^{2}$ will accept a profit-sharing ratio higher than that accepted by the low-type agent ${ }^{3}$.

Ajmi et al. (2019) analysed adverse selection in PLS contracts to determine which were optimal when there are market frictions. Relying on Monte Carlo simulation, they indicate that a high profit-sharing ratio is needed to avoid asymmetric information, meaning that such a ratio can avoid adverse selection.

Lessy et al. (2019) present a Markov chain model as a solution to adverse selection in PLS (mudarabah) contracts. According to them, the probability value of an applicant receiving investment from an Islamic bank will influence the possibility of adverse selection. They propose reducing the probability of applicants obtaining a PLS contract as a solution to avoid adverse selection.

Shapiro (2015) presents a model of incentive dynamics in which the lender knows little about the nature of borrowers in the future (there is information asymmetry between the lender and the borrower). He applies a Bayesian game in his analysis. The model developed is a model recurring loan if the agent is successful in repaying the loan; the model was developed by considering moral hazard or deliberate default by the agent.

Fakir and Tkiouat (2016) applied a Bayesian game to create a PLS contract, building their model with the aim of avoiding adverse selection in the contract. The model was developed for two cases, that of symmetric information and that of asymmetric information. They found that under the high probability of an efficient agent, the bank was not better off offering a higher type contract (a contract with a high profit-sharing ratio for agent).

The model built in our paper was inspired by Fakir and Tkiouat (2016), who proposed a Bayesian game model to reduce the adverse selection problem. We consider that they chose the right model (theory) to solve the problem. What distinguishes our model with theirs is that ours is presented from two different angles, with a model for non-social banks and social banks. The aim is to establish which bank provides the best solution for the agent and the bank. Based on the definition of the two types of bank of Benedikter (2011), it can be seen that they have different objectives. In the model, we will determine the Nash Bayesian equilibrium, which can be considered by Islamic banks as a solution to reducing adverse selection.

\section{METHODOLOGY}

\subsection{Data}

For the purposes of the simulation, we relied on Fakir and Tkiouat (2016) in setting the model parameters:

2. An agent with a high skill to run the project.

3. An agent with a low skill to run the project. 
An investment $k=10000$. If the offer of a contract from the Islamic bank is accepted by the agent, then the agent will receive investment $k=10000$ from the bank.

- The liquidating fraction of the investment $(L)=30 \%$. This means that the estimated percentage of the liquidation value of the investment in case of failure is $30 \%$.

- The income of contract $1\left(R_{1}\right)=6000$, so the income the agent receives from the project investment is 6000. On the other hand, the income of contract $2\left(R_{2}\right)=4000$, similarly meaning that the income the agent receives from the project investment is 4000 . Therefore, the agent's income from contract 1 is higher than that from contract 2 . The bank will tend to offer contract 1 to efficient agents, and contract 2 to non-efficient ones.

- $r_{1}=7.5 \%$ is the expected rate of return in the market for the bank for an investment risk level such as in contract 1, while the rate for a the risk level such as contract $2\left(r_{2}\right)=5 \%$. This means that the expected rate of return for the bank in contract 1 is greater than that in contract 2 .

The probability of success of an efficient agent in contract $1\left(\beta_{1}{ }^{E}\right)=80 \%$, while that in contract $2\left(\beta_{2}{ }^{\mathrm{E}}\right)=90 \%$, This means that the bank assigns $\beta_{1}{ }^{\mathrm{E}}=80 \%$ and $\beta_{2}{ }^{E}=90 \%$. Because contract 1 is more risky than contract 2, we assume that the probability of success for the efficient agent for contract 1 is lower than that in contract 2.

- The probability of success for a non-efficient agent in contract $1\left(\beta_{1}{ }^{E}\right)=60 \%$, while in contract 2 it is $\left(\beta_{2}{ }^{\neg E}\right)=80 \%$. This means that the bank assigns $\beta_{1}{ }^{-E}=60 \%$ and $\beta_{2}{ }^{-E}=80 \%$. Therefore, we assume that the probability of success of the nonefficient agent in contract 1 is lower than that in contract 2.

\subsection{Model Development}

We built a Bayesian game model for the PLS contract of a non-social and a social bank. The model was based on Fakir and Tkiouat (2016). While we borrowed certain setups, formulas and parameter values used in the simulation, our approach differed in that we applied the Bayesian Nash equilibrium as the solution to the game, for the Islamic banks to consider in mitigating the adverse selection problem in the PLS contract.

In our model, the game has two players, an Islamic bank $(B)$ (player 1) and a potential borrower $(A)$ (player 2), i.e. $N=\{B, A\}$. The incomplete information in our case refers to the bank not knowing the type of applicant (agent), and whether they are efficient or non-efficient. An efficient agent is one who is considered able to generate a large income from their business, while a non-efficient one is considered only able to generate a small income. The bank can determine the type of agent by studying the agent documents which are required when proposing an investment in the PLS contract. The bank can also determine the type of agent by interviewing them.

The bank can consider the type of agent with some probability. Let $p$ be a prior probability of the agent being efficient and 1- $p$ the probability of being nonefficient.

Player 1 (i.e. the bank) provides the capital. The bank offers one of two contracts, Contract $1\left(C_{1}\right)$ or Contract $2\left(C_{2}\right)$ representing an investment $k$ leading 
to an income from either contract $1\left(R_{1}\right)$ or contract $2\left(R_{2}\right)$, with the probability of success of contract $1\left(\beta_{1}\right)$ lower than that of contract $2\left(\beta_{2}\right), \beta_{1}<\beta_{2}$. C is a contract with a higher income than $C_{2^{\prime}} R_{1}>R_{2}$. Player 2 (i.e. the agent), who manages the enterprise, decides to accept or refuse the contract offered by the bank. The bank does not know what decision the agent will take. The agent has two actions, accept $(A c)$ or refuse $(R e)$.

We assume that in the event of the failure of the enterprise, the bank recovers only the liquidating fraction $L$ of its investment and thus suffers a loss (1- $L) k$. The agent is not penalised by the loss other than by not having received the wage $W$ that they would have earned if they had not entered into the contract. Both parties agree in advance on the profit-sharing ratio for agent $\rho_{i}$, and thus $1-\rho_{j}$ for the bank (for $j=1,2$, where $j$ is the name of the contract). We illustrate the game in Figure 2.

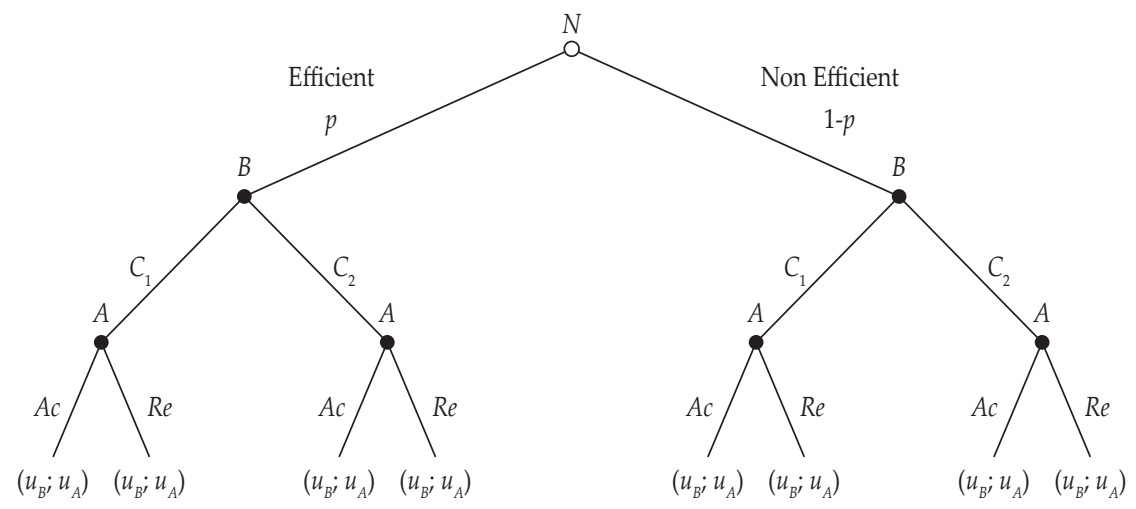

Figure 2.

Schematic Model of a Bayesian Game for a PLS Contract

If the agent accepts the contract offered by the bank, the payoff for the agent $\left(u_{A}\right)$ for any contract offered $C_{j}$ (for $j=1,2$, , where $j$ is the name of the contract).:

$$
u_{A}\left(C_{j}, A c\right)=\beta_{j} \rho_{j} R_{j}
$$

If the agent refuses the contract, $u_{A}$ is reduced for any contract offered $C_{j}$ :

$$
u_{A}\left(C_{j}, R e\right)=W
$$

If the agent accepts the contract, the payoff for the bank $\left(u_{B}\right)$ is:

$$
u_{B}\left(C_{j}, A c\right)=\beta_{j}\left(1-\rho_{j}\right) R_{j}-\left(1-\beta_{j}\right)(1-L) k \text {. }
$$

On the other hand, if $r_{j}$ is the expected rate of return in the market for the bank for the risk level of an investment such as the contract $C_{i}$, then whatever the agent's strategy, whether they accept or refuse the contract, we must also have:

$$
u_{B}\left(C_{j}, \cdot\right)=r_{j} k
$$


Therefore, if the agent accepts the contract offered by the bank, equation (3) is equal to equation (4).

$$
\beta_{j}\left(1-\rho_{j}\right) R_{j}-\left(1-\beta_{j}\right)(1-L) k=r_{j} k
$$

From equation (5), we can determine the profit-sharing ratio of the contract:

$$
1-\rho_{j}=\frac{r_{j} k+\left(1-\beta_{j}\right)(1-L) k}{\beta_{j} R_{j}}
$$

and

$$
\rho_{j}=1-\frac{r_{j} k+\left(1-\beta_{j}\right)(1-L) k}{\beta_{j} R_{j}}
$$

Note that if the probabilities of success of the efficient and non-efficient agents are different, for both $C_{1}$ and $C_{2}$ then the profit-sharing ratios for contract $C_{1}$ and contract $C_{2}$ are different.

In our model, the bank offers a contract $C_{j}$ with a profit and loss sharing ratio of agent $\rho$ for the efficient and non-efficient agents. Therefore, the determination of $\rho$ arises from incomplete information on the type of agent. To reduce the risk, the bank should offer a contract with a small $\rho$ for agents considered non-efficient, and conversely a contract with a large $\rho$ for those considered efficient.

The bank tends to offer contract $C_{1}$ to agents who are believed to be efficient and $C_{2}$ to those considered non-efficient in the hope that it will be accepted. Therefore, in our model equation (5) applies only to offer $C_{1}$ made to efficient agents and offer $C_{2}$ made to non-efficient agents.

In the following section, we will model the Bayesian game in the PLS contract for non-social and social banks.

\section{PLS Contract Model for the Non-social Bank}

We modelled the PLS contact for a non-social bank.

To build the model we assumed that

- the agent's income is higher if they accept contract 1 compared to contract 2 $\left(R_{1}>R_{2}\right)$, as contract 1 tends to be given to efficient agents (potential agents);

- the expected rate of return on the market for the risk level of an investment in contract $C_{1}$ is higher than that in contract $C_{2^{\prime}}\left(r_{1}>r_{2}\right)$;

- the probability of success in contract 1 by the efficient agent is lower than that in contract $2\left(\beta_{1}^{E}<\beta_{2}{ }^{E}\right)$. This also applies to the non-efficient agent $\left(\beta_{1}{ }^{E}<\beta_{2}{ }^{D E}\right)$. To determine the probability of success of the agent contract, the bank can use the borrower's historical data, namely the proportion of successful agents from the total agents who receive a contract;

- the profit-sharing ratio of contract 1 given to the efficient agent is higher than that of contract $2\left(\rho_{1}^{E}>\rho_{2}^{E}\right)$, but is similar for the non-efficient agent $\left(\rho_{1}^{\neg E}>\rho_{2}{ }^{D E}\right)$;

- the wage of the efficient agent is higher than that of the non-efficient agent $\left(W^{E}>W^{\urcorner}\right)$. 
Therefore, from the above assumptions, we can determine the payoff for the bank and the agent according to the strategy chosen by them. The payoff for the bank for agent strategies $A c$ and Re is the same, no matter what strategy the bank chooses. This applies to both the efficient and non-efficient agents. Using equation (3), we have the utilities of the bank, if the agent accepts the contract offered by the bank. We note the payoff for the bank if the type of agent is efficient $\left(u_{B}{ }^{E}\right)$ and the payoff for the bank if the type of agent is non-efficient $\left(u_{B}^{{ }^{E}}\right)$.

$$
\begin{aligned}
& u_{B}^{E}\left(C_{1}, A c\right)=\beta_{1}^{E}\left(1-\rho_{1}^{E}\right) R_{1}-\left(1-\beta_{1}^{E}\right)(1-L) k, \\
& u_{B}^{E}\left(C_{2}, A c\right)=\beta_{2}^{E}\left(1-\rho_{2}^{E}\right) R_{2}-\left(1-\beta_{2}^{E}\right)(1-L) k, \\
& \left.u_{B}^{E}\left(C_{1}, A c\right)=\beta_{1}\right\urcorner^{E}\left(1-\rho_{1}^{\urcorner}\right) R_{1}-\left(1-\beta_{1}^{E}\right)(1-L) k,
\end{aligned}
$$

and

$$
u_{B}^{E}\left(C_{2}, A c\right)=\beta_{2}^{\neg E}\left(1-\rho_{2}^{\neg E}\right) R_{2}-\left(1-\beta_{2}^{E}\right)(1-L) k .
$$

We can also use equation (4) to determine ${u_{B}}^{E}\left(C_{1}, A c\right)$ and $u_{B}{ }^{E}\left(C_{2}, A c\right)$.

$$
u_{B}^{E}\left(C_{1}, A c\right)=u_{B}^{E}\left(C_{1}, A c\right)=r_{1} k
$$

and

$$
u_{B}^{E}\left(C_{2}, A c\right)=u_{B}^{E}\left(C_{2}, A c\right)=r_{2} k
$$

Next, we used equation (4) to calculate the payoff for the bank if the agent refuses the contract offered.

$$
u_{B}^{E}\left(C_{1}, R e\right)=u_{B}^{E}\left(C_{1}, R e\right)=r_{1} k
$$

and

$$
u_{B}^{E}\left(C_{2}, R e\right)=u_{B}^{\neg}\left(C_{2}, R e\right)=r_{2} k
$$

Based on equation (1), if the agent accepts the contract, their payoff is the expectation of their profit, meaning the payoff of the efficient agent are

$$
u_{A}^{E}\left(C_{1}, A c\right)=\beta_{1}^{E} \rho_{1}^{E} R_{1}
$$

and

$$
u_{A}^{E}\left(C_{2}, A c\right)=\beta_{2}^{E} \rho_{2}^{E} R_{2},
$$

while the payoff of the non-efficient agent is:

$$
u_{A}^{\neg^{E}}\left(C_{1}, A c\right)=\beta_{1}^{E} \rho_{1}{ }^{E} R_{1}
$$


and

$u_{A}^{E}\left(C_{2}, A c\right)=\beta_{2}^{E} \rho_{2}{ }^{E} R_{2}$.

On the contrary, if the agent refuses the contract, their utility is only their wage (salary), whichever the contract offered by the bank, as shown in equation (2).

$u_{A}^{E}\left(C_{1}, R e\right)=u_{A}^{E}\left(C_{2}, R e\right)=W^{E}$

and

$\left.u_{A}^{\neg}\left(C_{1}, R e\right)=u_{A}\right\urcorner^{E}\left(C_{2}, R e\right)=W \neg E$

We present the payoffs for the bank and the agent in table 1 and table 2 . Based on equations (11), (12), (13), (14), (15), (16) and (19), we present these payoffs for the efficient agent type on the left-hand side of Table 1, while the right-hand side shows those of the bank and of the non-efficient type of agent, on the basis of equations (11), (12), (13), (14), (15), (17) and (20).

Table 1.

Bank and Agent Payoffs with Four Different Profit-Sharing Agent Ratios in the PLS Contract Model for the Non-Social Bank

\begin{tabular}{lcc}
\hline$(E)$ & $A c$ & $R \boldsymbol{e}$ \\
\hline$C_{1}$ & $r_{1} k ; \beta_{1}^{E} \rho_{1}{ }^{E} R_{1}$ & $r_{1} k ; W^{E}$ \\
$C_{2}$ & $r_{2} k ; \beta_{2}{ }^{E} \rho_{2}{ }^{E} R_{2}$ & $r_{2} k ; W^{E}$ \\
\hline
\end{tabular}

\begin{tabular}{lcc}
\hline$(\neg E)$ & $A c$ & $R \boldsymbol{e}$ \\
\hline$C_{1}$ & $r_{1} k ; \beta_{1}^{\neg E} \rho_{1}^{-E} R_{1}$ & $r_{1} k ; W^{-E}$ \\
$C_{2}$ & $r_{2} k ; \beta_{2}^{\neg E} \rho_{2}^{-E} R_{2}$ & $r_{2} k ; W^{-E}$ \\
\hline
\end{tabular}

We look for the equilibrium in pure strategy from each game for both situations in Table 1.

To find the equilibriums, two hypotheses were developed:

- $H^{E}: \beta_{1}{ }^{E} \rho_{1}{ }^{E} R_{1}>W^{E}$ and $\beta_{2}{ }^{E} \rho_{2}{ }^{E} R_{2}>W^{E}$ are rationalities.

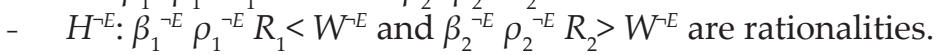

\section{Proposition 1:}

From hypothesis $H^{E},\left(C_{1}, A c\right)$ is a Nash equilibrium in pure strategy.

Proof:

We proceeded by eliminating the dominant strategies.

i. As we assumed that $r_{1}>r_{2}$, strategy $C_{1}$ is strictly dominated by strategy $C_{2}$.

ii. According to hypothesis $H^{E}$, the agent's best response to the bank's $C_{1}$ strategy is $A c$.

We therefore deduce from (i) and (ii) that $\left(C_{1}, A c\right)$ is a Nash equilibrium in pure strategy. 


\section{Proposition 2:}

From hypothesis $H^{\urcorner E},\left(C_{1}, R e\right)$ is a Nash equilibrium in pure strategy.

Proof:

We proceeded by eliminating dominant strategies.

i. As we assumed that $r_{1}>r_{2^{\prime}}$ strategy $C_{1}$ is strictly dominated by strategy $C_{2}$.

ii. According to hypothesis $H^{\urcorner E}$, the agent's best response to the bank's $C_{1}$ strategy is $R e$.

We therefore deduce from (i) and (ii) that $\left(C_{1}, R e\right)$ is a Nash equilibrium in pure strategy.

From propositions 1 and 2 , we find that $\left(C_{1}, A c\right)$ and $\left(C_{1}, R e\right)$ are Nash equilibriums in the pure strategies respectively. This means that the bank offers contract $C_{1}$ to efficient and non-efficient agents; the efficient agent accepts the contract, while the non-efficient one rejects it.

This result is satisfactory for the efficient agent because they receive a contract with a high profit-sharing ratio; on the other hand, it is not satisfactory for the nonefficient agent because they cannot access a contract.

In order for agents to access a contract from the bank, whatever the type, we now consider offering contract $C_{1}$ to an efficient agent and contract $C_{2}$ to a nonefficient agent. We set the profit-sharing ratio as:

$$
\rho_{1}=\rho_{1}^{E}
$$

and

$$
\rho_{2}=\rho_{2}^{\neg E}
$$

For this, we used $\beta_{1}{ }^{E}$ to compute $\rho_{1}$ and $\beta_{2}{ }^{E}$ to compute $\rho_{2}$. As a consequence, several bank and agent payoffs change:

$$
\begin{aligned}
& u_{B}^{E}\left(C_{2}, A c\right)=\beta_{2}^{E}\left(1-\rho_{2}\right) R_{2}-\left(1-\beta_{2}^{E}\right)(1-L) k, \\
& \left.u_{B}^{E}\left(C_{1}, A c\right)=\beta_{1}^{E}\left(1-\rho_{1}\right) R_{1}-\left(1-\beta_{1}\right\urcorner^{E}\right)(1-L) k, \\
& u_{A}^{E}\left(C_{2}, A c\right)=\beta_{2}^{E} \rho_{2} R_{2},
\end{aligned}
$$

and

$$
u_{A}{ }^{E}\left(C_{1}, A c\right)=\beta_{1}^{E} \rho_{1} R_{1}
$$

Considering the assigning of share rates to equations (21) and (22), and changing some of the bank and agent payoffs in equations (23), (24), (25) and (26), we present new payoffs for efficient and non-efficient agent types in Table 2. 
Table 2.

Bank and Agent Payoffs with Two Different Profit-Sharing Agent Ratios in the PLS Contract Model for the Non-Social Bank

\begin{tabular}{lcc}
\hline$(E)$ & $A c$ & $R e$ \\
\hline$C_{1}$ & $\beta_{1}^{E}\left(1-\rho_{1}\right) R_{1}-\left(1-\beta_{1}{ }^{E}\right)(1-L) k ; \beta_{1}^{E} \rho_{1} R_{1}$ & $r_{1} k ; W^{E}$ \\
$C_{2}$ & $\beta_{2}^{E}\left(1-\rho_{2}\right) R_{2}-\left(1-\beta_{2}{ }^{E}\right)(1-L) k ; \beta_{2}{ }^{E} \rho_{2} R_{2}$ & $r_{2} k ; W^{E}$ \\
\hline & $A c$ & $R e$ \\
\hline$(\neg E)$ & $A c$ & $r_{1} k ; W^{-E}$ \\
\hline$C_{1}$ & $\beta_{1}{ }^{-E}\left(1-\rho_{1}\right) R_{1}-\left(1-\beta_{1}{ }^{-E}\right)(1-L) k ; \beta_{1}{ }^{-E} \rho_{1} R_{1}$ & $r_{2} k ; W^{-E}$ \\
$C_{2}$ & $\beta_{2}{ }^{-E}\left(1-\rho_{2}\right) R_{2}-\left(1-\beta_{2}{ }^{-E}\right)(1-L) k ; \beta_{2}{ }^{-E} \rho_{2} R_{2}$ & \\
\hline
\end{tabular}

We next discuss the game with incomplete information. Recall that $p$ is the prior probability of the agent being efficient and 1- $p$ the probability of their being non-efficient. We have the bank's and agent's strategies, and the strategic space for each player.

$S_{B}=\left\{C_{1}, C_{2}\right\}$ and $\left.S_{A}=\left\{A c^{E} A c^{E}, A c^{E} R e^{E}, R e^{E} A c\right\urcorner E, R e^{E} R e^{E}\right\}$

Next, we calculated the expected payoff of each strategy.

- The strategy if the bank offers contract $C_{1}$, which the efficient agent and the non-efficient agent accept $\left(C_{1}, A c^{E} A c^{-E}\right)$ with its associated expected payoff.

$$
\begin{aligned}
& E\left[u_{B}\left(C_{1}, A c^{E} A c^{E}\right)\right] \\
& =\left(\left(\beta_{1}^{E}-\beta_{1}^{E}\right)\left(\left(1-\rho_{1}\right) R_{1}+(1-L) k\right)\right) p+\left(\beta_{1}\right\urcorner^{E}\left(1-\rho_{1}\right) R_{1} \\
& \left.-\left(1-\beta_{1}^{E}\right)(1-L) k\right) \\
& E\left[u_{A}\left(C_{1}, A c^{E} A c^{E}\right)\right]=\left(\beta_{1}^{E}-\beta_{1}^{E}\right) \rho_{1} R_{1} p+\beta_{1}^{E} \rho_{1} R_{1}
\end{aligned}
$$

The strategy if the bank offers contract $C_{1}$, which the efficient agent accepts, while the non-efficient agent refuses $\left(C_{1}, A c^{E} R e^{E}\right)$ with its associated expected payoff.

$E\left[u_{B}\left(C_{1}, A c^{E} R e^{\neg E}\right)\right]=r_{1} k$

$E\left[u_{A}\left(C_{1}, A c^{E} R e^{E}\right)\right]=\left(\beta_{1}^{E} \rho_{1} R_{1}-W \neg E\right) p+W \neg E$

- The strategy if the bank offers contract $C_{1}$, which the efficient agent refuses, while the non-efficient agent accepts $\left(C_{1}, R e^{E} A c^{-E}\right)$ with its associated expected payoff.

$$
\begin{aligned}
& E\left[u_{B}\left(C_{1}, R e^{E} A c^{E}\right)\right] \\
& =\left(r_{1} k-\left(\beta_{1}^{E}\left(1-\rho_{1}\right) R_{1}-\left(1-\beta_{1}^{E}\right)(1-L) k\right)\right) p \\
& +\left(\beta_{1}^{E}\left(1-\rho_{1}\right) R_{1}-\left(1-\beta_{1} E\right)(1-L) k\right) \\
& \left.E\left[u_{A}\left(C_{1}, R e^{E} A c^{E}\right)\right]=\left(W^{E}-\beta_{1}\right\urcorner^{E} \rho_{1} R_{1}\right) p+\beta_{1}^{E} \rho_{1} R_{1}
\end{aligned}
$$


- The strategy if the bank offers contract $C_{1}$, which the efficient agent and the non-efficient agent refuse $\left(C_{1}, R e^{E} R e^{-E}\right)$ with its associated expected payoff

$$
\begin{aligned}
& E\left[u_{B}\left(C_{1}, R e^{E} R e^{E}\right)\right]=r_{1} k \\
& E\left[u_{A}\left(C_{1}, \operatorname{Re}^{E} R e^{E}\right)\right]=\left(W^{E}-W \neg E\right) p+W \neg E
\end{aligned}
$$

- The strategy if the bank offers contract $C_{2}$, which the efficient agent and the non-efficient agent accept $\left(C_{2^{\prime}} A c^{E} A c^{\urcorner E}\right)$ with its associated expected payoff.

$$
\begin{aligned}
& \left.E\left[u_{B}\left(C_{2}, A c^{E} A c\right\urcorner^{E}\right)\right] \\
& =\left(\left(\beta_{2}^{E}-\beta_{2}^{E}\right)\left(\left(1-\rho_{2}\right) R_{2}+(1-L) k\right)\right) p+\left(\beta_{2}^{E}\left(1-\rho_{2}\right) R_{2}\right. \\
& \left.-\left(1-\beta_{2}^{E}\right)(1-L) k\right) \\
& E\left[u_{A}\left(C_{2}, A c^{E} A c^{E}\right)\right]=\left(\beta_{2}^{E}-\beta_{2}^{E}\right) \rho_{2} R_{2} p+\beta_{2}^{E} \rho_{2} R_{2}
\end{aligned}
$$

- The strategy if the bank offers contract $C_{2}$, which the efficient agent accepts, while the non-efficient agent refuses $\left(C_{2^{\prime}} A c^{E} R e^{-E}\right)$ with its associated expected payoff.

$$
\begin{aligned}
& E\left[u_{B}\left(C_{2}, A c^{E} R e^{E}\right)\right]=\left(\beta_{2}^{E}\left(1-\rho_{2}\right) R_{2}-\left(1-\beta_{2}^{E}\right)(1-L) k-r_{2} k\right) p+r_{2} k \\
& \left.E\left[u_{A}\left(C_{2}, A c^{E} R e^{E}\right)\right]=\left(\beta_{2}^{E} \rho_{2} R_{2}-W\right\urcorner^{E}\right) p+W{ }^{E}
\end{aligned}
$$

- The strategy if the bank offers contract $C_{2}$, which the efficient agent refuses, while the non-efficient agent accepts $\left(C_{2^{\prime}} R e^{E} A c^{-E}\right)$ with its associated expected payoff.

$$
\begin{aligned}
& E\left[u_{B}\left(C_{2}, R e^{E} A c^{E}\right)\right]=r_{2} k \\
& \left.E\left[u_{A}\left(C_{2}, R e^{E} A c^{E}\right)\right]=\left(W^{E}-\beta_{2}\right\urcorner^{E} \rho_{2} R_{2}\right) p+\beta_{2}^{E} \rho_{2} R_{2}
\end{aligned}
$$

- The strategy if the bank offers contract $C_{2}$, which the efficient agent and the non-efficient agent refuse $\left(C_{2^{\prime}} R e^{E} R e^{-E}\right)$ with its associated expected payoff.

$$
\begin{aligned}
& E\left[u_{B}\left(C_{2}, R e^{E} R e^{E}\right)\right]=r_{2} k \\
& E\left[u_{A}\left(C_{2}, R e^{E} R e^{E}\right)\right]=\left(W^{E}-W \neg E\right) p+W \neg E
\end{aligned}
$$

To avoid or mitigate adverse selection, when the bank offers contract $C_{1}$ with a high profit- sharing agent ratio $\left(\rho_{1}\right)$, it is accepted by the efficient agent and refused by the non-efficient agent because contract $C_{1}$ is more risky for them. If the non-efficient agent accepts this contract, it will be risky and lead to potential bank loss. On the contrary, to avoid or reduce adverse selection, when the bank offers contract $C_{2}$ with a low profit-sharing agent ratio $\left(\rho_{2}\right)$, it is refused by the efficient agent and accepted by the non-efficient agent because the contract is less risky for the non-efficient agent but not profitable for the efficient agent. The efficient agent is a potential agent in production and hence should be able to secure a better contract. 
In our model, the above conditions can be described in terms of the Nash Bayesian equilibriums. To avoid or reduce adverse selection, we expect the Bayesian Nash equilibrium to be $\left(C_{1}, A c^{E} R e^{-E}\right)$ and $\left(C_{2^{\prime}} R e^{E} A c^{\urcorner E}\right)$.

\section{PLS Contract Model for the Social Bank}

We propose an alternative utility which we call social utility. If the bank is an organisation with a social purpose, it can, without giving up its, adopt for example as its utility, the sum of its expectation and that of its agent's expectation,

$$
u_{B}^{S}=u_{B}+u_{A}
$$

In this model, we keep the hypothesis introduced in the section describing the PLS contract model for the non-social bank, namely $R_{1}>R_{2^{\prime}}, r_{1}>r_{2^{\prime}}, \beta_{1}^{E}<\beta_{2}{ }^{E}, \beta_{1}{ }^{E}<\beta_{2}{ }^{\beth E}, \rho_{1}$ $>\rho_{2}$ and $W^{E}>W^{E}$.

We used $u_{B}$ and $u_{A}$ in the non-social bank PLS contract model to determine the payoffs of the bank and the agent in the social bank PLS contract model by using equation (27).

Table 3.

Payoffs for the Bank and Agent with Complete Information in the Social Bank PLS Contract Model.

\begin{tabular}{llc}
\hline$(E)$ & $A c^{E}$ & $\operatorname{Re}^{E}$ \\
\hline$C_{1}$ & $\beta_{1}^{E} R_{1}-\left(1-\beta_{1}^{E}\right)(1-L) k ; \beta_{1}^{E} \rho_{1} R_{1}$ & $r_{1} k+W^{E} ; W^{E}$ \\
$C_{2}$ & $\beta_{2}^{E} R_{2}-\left(1-\beta_{2}^{E}\right)(1-L) k ; \beta_{2}^{E} \rho_{2} R_{2}$ & $r_{2} k+W^{E} ; W^{E}$ \\
\hline
\end{tabular}

\begin{tabular}{llc}
\hline$(\neg E)$ & $A c^{\neg E}$ & $R e\urcorner^{E}$ \\
\hline$C_{1}$ & $\left.\beta_{1}{ }^{E} R_{1}-\left(1-\beta_{1}\right\urcorner^{E}\right)(1-L) k ; \beta_{1}{ }^{E} \rho_{1} R_{1}$ & $\left.r_{1} k+W\right\urcorner E ; W \neg E$ \\
\hline$C_{2}$ & $\left.\left.\beta_{2}{ }^{E} R_{2}-\left(1-\beta_{2}\right\urcorner^{E}\right)(1-L) k ; \beta_{2}\right\urcorner^{E} \rho_{2} R_{2}$ & $\left.r_{2} k+W\right\urcorner E ; W \neg E$ \\
\hline
\end{tabular}

In the non-social bank model, we look for Bayesian Nash equilibrium, which will be a solution to avoid adverse selection. We establish the bank's and agent's strategies, and the strategic space for each player.

$S_{B}=\left\{C_{1}, C_{2}\right\}$ and $S_{A}=\left\{A c^{E} A c^{E}, A c^{E} R e^{2 E}, R e^{E} A c^{E}, R e^{E} R e^{\neg E}\right\}$

Next, we calculate the expected payoff from each strategy, namely:

- The strategy if the bank offers contract $C_{1}$, which the efficient agent and the non-efficient agent accept $\left(C_{1}, A c^{E} A c^{\urcorner E}\right)$ with its associated expected payoff.

$$
\begin{aligned}
& \left.E\left[u_{B}\left(C_{1}, A c^{E} A\right\urcorner^{E}\right)\right] \\
& =\left(\left(\beta_{1}^{E}-\beta_{1}^{E}\right) R_{1}+(1-L) k\right) p+\left(\beta_{1}{ }^{E} R_{1}-\left(1-\beta_{1}^{E}\right)(1-L) k\right) \\
& \left.E\left[u_{A}\left(C_{1}, A c^{E} A c^{E}\right)\right]=\left(\beta_{1}^{E}-\beta_{1}\right\urcorner^{E}\right) \rho_{1} R_{1} p+\beta_{1}^{E} \rho_{1} R_{1}
\end{aligned}
$$


- The strategy if the bank offers contract $C_{1}$, which the efficient agent accepts, while the non-efficient agent refuses $\left(C_{1}, A c^{E} R e^{-E}\right)$ with its associated expected payoff

$$
\begin{aligned}
& E\left[u_{B}\left(C_{1}, A c^{E} R e^{E}\right)\right]=\left(\beta_{1}^{E} R_{1}-\left(\left(1-\beta_{1}^{E}\right)(1-L)+r_{1}\right) k-W \neg E\right) p+r_{1} k+W \neg E \\
& E\left[u_{A}\left(C_{1}, A c^{E} R e^{E}\right)\right]=\left(\beta_{1}^{E} \rho_{1} R_{1}-W \neg E\right) p+W \neg E
\end{aligned}
$$

- The strategy if the bank offers contract $C_{1}$, which the efficient agent refuses, while the non-efficient agent accepts $\left(C_{1}, R e^{E} A c^{\urcorner E}\right)$ with its associated expected payoff

$$
\begin{aligned}
& E\left[u_{B}\left(C_{1}, R e^{E} A c^{E}\right)\right] \\
& \left.\left.=\left(\left(r_{1}+\left(1-\beta_{1}\right\urcorner^{E}\right)(1-L)\right) k+W^{E}-\beta_{1}\right\urcorner^{E} R_{1}\right) p+\beta_{1}^{E} R_{1} \\
& -\left(1-\beta_{1}^{E}\right)(1-L) k \\
& \left.E\left[u_{A}\left(C_{1}, R e^{E} A c^{E}\right)\right]=\left(W^{E}-\beta_{1}\right\urcorner^{E} \rho_{1} R_{1}\right) p+\beta_{1} \rho_{1} \rho_{1}
\end{aligned}
$$

- The strategy if the bank offers contract $C_{1}$, which the efficient agent the nonefficient agent refuse $\left(C_{1}, R e^{E} R e^{-E}\right)$ with its associated expected payoff

$$
\begin{aligned}
& E\left[u_{B}\left(C_{1}, R e^{E} R e^{\neg E}\right)\right]=\left(W^{E}-W \neg E\right) p+r_{1} k+W \neg E \\
& E\left[u_{A}\left(C_{1}, R e^{E} R e^{E}\right)\right]=\left(W^{E}-W \neg E\right) p+W W^{E}
\end{aligned}
$$

- The strategy if the bank offers contract $C_{2}$, which the efficient agent and the non-efficient agent accept $\left(C_{2}, A c^{E} A c^{\urcorner E}\right)$ with its associated expected payoff

$$
\begin{aligned}
& \left.E\left[u_{B}\left(C_{2}, A c^{E} A c\right\urcorner^{E}\right)\right] \\
& =\left(\left(\beta_{2}^{E}-\beta_{2}^{E}\right) R_{2}+(1-L) k\right) p+\left(\beta_{2}{ }^{E} R_{2}-\left(1-\beta_{2}^{E}\right)(1-L) k\right) \\
& \left.\left.E\left[u_{A}\left(C_{2}, A c^{E} A\right\urcorner^{E}\right)\right]=\left(\beta_{2}^{E}-\beta_{2}\right\urcorner^{E}\right) \rho_{2} R_{2} p+\beta_{2}^{E} \rho_{2} R_{2}
\end{aligned}
$$

- The strategy if the bank offers contract $C_{2^{\prime}}$ which the efficient agent accepts, while the non-efficient agent refuses $\left(C_{2^{\prime}} A c^{E} R e^{-E}\right)$ with its associated expected payoff

$$
\begin{aligned}
& E\left[u_{B}\left(C_{2}, A c^{E} R e^{E}\right)\right] \\
& \left.=\left(\beta_{2}^{E} R_{2}-\left(\left(1-\beta_{2}^{E}\right)(1-L) k-r_{2}\right) k-W \neg E\right) p+r_{2} k+W\right\urcorner E \\
& E\left[u_{A}\left(C_{2}, A c^{E} R e^{E}\right)\right]=\left(\beta_{2}^{E} \rho_{2} R_{2}-W \neg E\right) p+W \neg E
\end{aligned}
$$

- The strategy if the bank offers contract $C_{2^{\prime}}$, which the efficient agent refuses, while the non-efficient agent accepts $\left(C_{2^{\prime}} R e^{E} A c^{\urcorner E}\right)$ with its associated expected payoff

$$
\begin{aligned}
& E\left[u_{B}\left(C_{2}, R e^{E} A c^{E}\right)\right] \\
& =\left(\left(r_{2}+\left(1-\beta_{2}^{E}\right)(1-L)\right) k+W^{E}-\beta_{2}{ }^{E} R_{2}\right) p+\beta_{2}{ }^{E} R_{2} \\
& \left.-\left(1-\beta_{2}\right\urcorner^{E}\right)(1-L) k \\
& E\left[u_{A}\left(C_{2}, R e^{E} A c^{E}\right)\right]=\left(W^{E}-\beta_{2}{ }^{E} \rho_{2} R_{2}\right) p+\beta_{2}{ }^{E} \rho_{2} R_{2}
\end{aligned}
$$


- The strategy if the bank offers contract $C_{2^{\prime}}$ which the efficient agent and the non-efficient agent refuse $\left(C_{2^{\prime}} R e^{E} R e^{-E}\right)$ with its associated expected payoff

$$
\begin{aligned}
& E\left[u_{B}\left(C_{2}, R e^{E} R e^{E}\right)\right]=\left(W^{E}-W{ }^{E}\right) p+r_{2} k+W \neg E \\
& \left.\left.E\left[u_{A}\left(C_{2}, \operatorname{Re}^{E} \operatorname{Re}\right\urcorner^{E}\right)\right]=\left(W^{E}-W\right\urcorner E\right) p+W{ }^{E}
\end{aligned}
$$

Similar to the non-social bank model, in order to avoid or reduce adverse selection we expect the Bayesian Nash equilibrium to be $\left(C_{1}, A c^{E} \operatorname{Re}^{-E}\right)$ and $\left(C_{2^{\prime}} R e^{E} A c^{-E}\right)$.

\section{RESULTS AND ANALYSIS}

In this section, we present examples of the application of the Bayesian game in a PLS contract, both for social and non-social banks. In each example, we look for the Nash Bayesian equilibrium and analyse the results obtained.

\subsection{Results}

\section{Example of the Non-Social Bank PLS Contract Model}

We assume that $k=10000, R_{1}=6000, R_{2}=4000, \mathrm{~L}=30 \%=0.3, r_{1}=7.5 \%=0.075$ and $r_{2}=5 \%=0.05$. Suppose also that the probabilities of success of the efficient agent for $C_{1}$ and $C_{2}$ are respectively:

$$
\beta_{1}{ }^{E}=80 \% \text { and } \beta_{2}{ }^{E}=90 \% \text {, }
$$

while the probabilities of success of the non-efficient agent for $C_{1}$ and $C_{2}$ are respectively:

$$
\beta_{1}{ }^{-E}=60 \% \text { and } \beta_{2}{ }^{\mathrm{E}}=80 \% \text {. }
$$

If we determine $\rho$ of each contract using equation (6), we obtain

$$
\rho_{1}^{E}=55.2 \%, \rho_{2}^{E}=66.7 \%, \rho_{1}^{\neg E}=1.4 \% \text {, and } \rho_{2}^{\neg E}=40.6 \% \text {. }
$$

Formulas (15) and (16) give the following payoffs for the efficient agent, if it accepts contracts $C_{1}$ and $C_{2}$ respectively:

$u_{A}{ }^{E}\left(C_{1}, A c\right)=2650$ and $u_{A}{ }^{E}\left(C_{2^{\prime}} A c\right)=2400$.

Using equations (17) and (18), the payoffs for the non-efficient agent are:

$u_{A}^{\neg E}\left(C_{1}, A c\right)=50$ and $u_{A}^{\neg E}\left(C_{2}, A c\right)=1300$.

If the efficient agent refuses the contract, as indicated in formula (19), it keeps the agent's salary $W=W^{E}=500$, and therefore, whatever the contract, we have

$$
u_{A}^{E}\left(C_{1}, R e\right)=u_{A}^{E}\left(C_{2}, R e\right)=400 .
$$


On the other hand, using equation (20) to calculate the payoffs of the nonefficient agent, if this agent refuses the contract,

$$
u_{A}^{E}\left(C_{1}, R e\right)=u_{A}{ }^{E}\left(C_{2}, R e\right)=200 .
$$

Next, we determine the bank payoffs for the cases of the efficient and nonefficient agents, regardless of the strategy chosen by the agent, with equation (4):

$$
u_{B}^{E}\left(C_{1}, \bullet\right)=u_{B}^{\neg^{E}}\left(C_{1}, \bullet\right)=750
$$

and

$u_{B}^{E}\left(C_{2}, \bullet\right)=u_{B} E\left(C_{2}, \bullet\right)=500$.

We present all the payoffs calculated above in Table 4 .

Table 4.

Payoffs of the Bank and Agent Using Four Different Profit-Sharing Agent Ratios in the Example of the Non-Social Bank PLS Contract Model

\begin{tabular}{lcc}
\hline$(E)$ & $A \boldsymbol{c}^{E}$ & $\boldsymbol{R} \boldsymbol{e}^{E}$ \\
\hline$C_{1}$ & $750 ; 2650$ & $750 ; 400$ \\
$C_{2}$ & $500 ; 2400$ & $500 ; 400$ \\
\hline
\end{tabular}

\begin{tabular}{lcc}
\hline$(\neg E)$ & $A c^{\neg E}$ & $\boldsymbol{R} \boldsymbol{e}^{\urcorner E}$ \\
\hline$C_{1}$ & $750 ; 50$ & $750 ; 200$ \\
$C_{2}$ & $500 ; 1300$ & $500 ; 200$ \\
\hline
\end{tabular}

We can easily check if the strategies in Table $4,(750 ; 2650)$ and $(750 ; 200)$, are the Nash equilibriums in pure strategies.

These results are satisfactory in the case of an efficient agent, but socially disappointing for a non-efficient agent, who will never accept contract $C_{1}$ offered by the bank, whereas contract $C_{2}$ would be advantageous to this type of agent, even if not optimal for the bank.

We now consider offering contract $C_{1}$ to the efficient agent and contract $C_{2}$ to the non-efficient agent.

To avoid risks, the bank tends to offer contract $C_{1}$ to the efficient agent and contract $C_{2}$ to the non-efficient agent, so we use $\beta_{1}{ }^{E}$ to determine the profit sharing ratio of $C_{1}$ for agent $\left(\rho_{1}\right)$ while $\beta_{2}{ }^{-E}$ is used to determine the ratio of $C_{2}$ for agent $\left(\rho_{2}\right)$. We obtain

$$
\rho_{1}=55.2 \% \text { and } \rho_{2}=40.67 \% \text {. }
$$

We next determine the payoffs for the bank in the case of the efficient agent $\left(u_{B}{ }^{E}\right)$ and and of non-efficient agent $\left(u_{B}{ }^{E}\right)$. If the agent accepts, we use equation (3) to calculate these.

$$
u_{B}^{E}\left(C_{1}, A c\right)=750, u_{B}^{E}\left(C_{2}, A c\right)=1437.5, u_{B}^{\neg}\left(C_{1}, A c\right)=-1187.5 \text {, and } u_{B}^{\nabla}\left(C_{2}, A c\right)=500 .
$$

We can also use equation (4) to confirm $u_{B}{ }^{E}\left(C_{1}, A c\right)$ and $u_{B}{ }^{E}\left(C_{2^{\prime}}, A c\right)$. This equation is then used to calculate the bank payoffs if the agent refuses the contract offered. 


$$
u_{B}^{E}\left(C_{1}, R e\right)=u_{B}^{\neg}\left(C_{1}, R e\right)=750 \text { and } u_{B}^{E}\left(C_{2}, R e\right)=u_{B}^{E}\left(C_{2}, R e\right)=500
$$

Formula (1) gives the following payoffs for the efficient agent $\left(u_{A}{ }^{E}\right)$ and the non-efficient agent $\left(u_{B}{ }^{E}\right)$, if they accept:

$$
u_{A}^{E}\left(C_{1}, A c\right)=2650, u_{B}^{E}\left(C_{2}, A c\right)=1462.5, u_{B}^{\neg E}\left(C_{1}, A c\right)=1987.5 \text {, and } u_{B}^{\neg E}\left(C_{2}, A c\right)=1300 .
$$

If the efficient agent refuses the contract, it keeps its salary $W=W^{E}=400$, as indicated in formula (2). Therefore, whatever the contract $C_{j^{\prime}}$, we obtain

$$
u_{A}^{E}\left(C_{1}, R e\right)=u_{A}^{E}\left(C_{2}, R e\right)=W^{E}=400
$$

On the other hand, if the non-efficient agent refuses the contract, it keeps its salary $W=W^{E}=200$ (less than the salary of the efficient agent); therefore, whatever the contract $C_{i}$, we have

$$
\left.u_{A}\right\urcorner^{E}\left(C_{1}, R e\right)=u_{A}^{\urcorner^{E}}\left(C_{2}, R e\right)=W \neg E=200 .
$$

We present all the payoffs calculated above in Table 5.

Table 5.

Payoffs of the Bank and Agent with Two Different Profit-Sharing Agent Ratios in the Example of the Non-Social Bank PLS Contract Model

\begin{tabular}{lcc}
\hline$(E)$ & $\boldsymbol{A c} \boldsymbol{c}^{E}$ & $\boldsymbol{R} \boldsymbol{e}^{E}$ \\
\hline$C_{1}$ & $750 ; 2650$ & $750 ; 400$ \\
$C_{2}$ & $1437.5 ; 1462.5$ & $500 ; 400$ \\
\hline
\end{tabular}

\begin{tabular}{lcc}
\hline$(\neg E)$ & $A \boldsymbol{c}^{\neg E}$ & $\boldsymbol{R} \boldsymbol{e}^{-E}$ \\
\hline$C_{1}$ & $-1187.5 ; 1987.5$ & $750 ; 200$ \\
$C_{2}$ & $500 ; 1300$ & $500 ; 200$ \\
\hline
\end{tabular}

We can easily check if the strategies in Table $5,(1437.5 ; 1462.5)$ and $(500 ; 1300)$ are the Nash equilibrium in pure strategies.

This result is barely satisfactory in the case of an efficient agent since only contract $C_{2}$ designed for a non-efficient agent gives rise to a Nash equilibrium.

We have considered an example of a game between banks and agents using complete information. We will now do so with incomplete information, when the bank does not know the type of applicant (agent), and whether they are an efficient or non-efficient agent. The bank assigns the type of agent a certain probability. Let $p$ be the a priori probability that the bank assigns the agent to the efficient category, then 1- $p$ is the probability of the non-efficient agent type.

We looked for Bayesian Nash equilibriums. We first calculated the expected payoffs from each strategy using the formulas in section 3.1, which are shown in Table 6. 
Table 6.

Expected Bank and Agent Payoffs in the Non-Social Bank Bayesian Games Model

\begin{tabular}{ccccc}
\hline & $A c^{E} A c^{-E}$ & $A c^{E} \boldsymbol{R} e^{-E}$ & $\boldsymbol{R} \boldsymbol{e}^{E} \boldsymbol{A c ^ { - E }}$ & $\boldsymbol{R} \boldsymbol{e}^{E} \boldsymbol{R} \boldsymbol{e}^{-E}$ \\
\hline$C_{1}$ & $1937.5 p-1187.5 ;$ & $750 ; 2450 p+200$ & $1937.5 p-1187.5 ;$ & $750 ; 200 p+200$ \\
& $662.5 p+1987.5$ & $937.5 p+500 ;$ & $-1587.5 p+1987.5$ & \\
$C_{2}$ & $937.5 p+500 ;$ & $1262.5 p+200$ & $500 ;-900 p+1300$ & $500 ; 200 \mathrm{p}+200$ \\
\hline
\end{tabular}

To determine $p$, we compared the utility of the bank in contracts $C_{1}$ and $C_{2}$ (for all agent strategies). In addition, we compared the utility of the agent in strategies $A c^{E} A c^{\urcorner E}, A c^{E} R e^{-E}, \operatorname{Re}^{E} A c^{\urcorner}$, and $\operatorname{Re}^{E} \operatorname{Re}^{\urcorner E}$ (for all bank strategies). We considered the $p$ that satisfied the probability rule $(p \in[0,1])$.

\section{Proposition 3:}

Based on the utilities in Table 6, $\left(C_{2}, A c^{E} A c^{-E}\right)$ is a Bayesian Nash equilibrium for all $p$.

Proof:

If the agent's strategy is $A c^{E} A c^{-E}, C_{2}$ is preferable to $C_{1}$ for the bank because $937.5 p+500 \geq 1937.5 p-1187.5$.

If the bank's strategy is $C_{2^{\prime}} A c^{E} A c^{-E}$ is preferable to the agent's other three strategies because $162.5 p+1300 \geq 1262.5 p+200,162.5 p+1300 \geq-900 p+1300$, and $162.5 p+1300 \geq 200 p+200$. Therefore, strategy $\left(C_{2^{\prime}} A c^{E} A c^{-E}\right)$ is a Bayesian Nash equilibrium.

We will chose certain values of $p$ to ascertain the Bayesian Nash equilibrium.

For $p=0.2$, we found the payoffs of all the bank and agent strategies, as shown in Table 7.

Table 7.

Bank and Agent Payoffs for $p=0.2$ in the Non-Social Bank PLS Contract

\begin{tabular}{lcccc}
\hline & $\boldsymbol{A} \boldsymbol{c}^{E} \boldsymbol{A} \boldsymbol{c}^{-E}$ & $\boldsymbol{A \boldsymbol { c } ^ { E } \boldsymbol { R } \boldsymbol { e } ^ { - E }}$ & $\boldsymbol{R} \boldsymbol{e}^{E} \boldsymbol{A} \boldsymbol{c}^{-E}$ & $\boldsymbol{R} \boldsymbol{e}^{E} \boldsymbol{R} \boldsymbol{e}^{-E}$ \\
\hline$C_{1}$ & $-800 ; 2120$ & $750 ; 690$ & $-800 ; 1670$ & $750 ; 240$ \\
$C_{2}$ & $687.5 ; 1332.5$ & $687.5 ; 452.5$ & $500 ; 1120$ & $500 ; 240$ \\
\hline
\end{tabular}

By eliminating the dominant strategies, we could easily verify from the strategies in bold in Table 7 that $\left(C_{2}, A c^{E} A c^{-E}\right)$ is a Bayesian Nash equilibrium. This means that for $p=0.2$ the bank offers contract $C_{2}$ with a low profit-sharing agent ratio $\left(\rho_{2}\right)$ to both types of agents, both of whom accept it.

We then used another $p$ in the payoff calculation. We chose $p=\frac{2}{3}$, with the bank and agent payoffs shown in Table 8 . 
Table 8.

Bank and Agent Payoffs for $\boldsymbol{p}=\frac{2}{3}$ in the Non-Social Bank PLS Contract Model

\begin{tabular}{lcccc}
\hline & $\boldsymbol{A} \boldsymbol{c}^{E} \boldsymbol{A} \boldsymbol{c}^{\urcorner E}$ & $\boldsymbol{A \boldsymbol { c } ^ { E }} \boldsymbol{R} \boldsymbol{e}^{-E}$ & $\boldsymbol{R} \boldsymbol{e}^{E} \boldsymbol{A} \boldsymbol{c}^{-E}$ & $\boldsymbol{R} \boldsymbol{e}^{E} \boldsymbol{R} \boldsymbol{e}^{-E}$ \\
\hline$C_{1}$ & $104.2 ; 2429.2$ & $750 ; 1833.3$ & $104.2 ; 929.2$ & $750 ; 333.3$ \\
$C_{2}$ & $1125 ; 1403.8$ & $1125 ; 1041.7$ & $500 ; 700$ & $500 ; 333.3$ \\
\hline
\end{tabular}

For $p=\frac{2}{3}$, we also found that $\left(C_{2^{\prime}} A c^{E} A c^{\urcorner E}\right)$ is a Bayesian Nash equilibrium. This means that for $p=\frac{2}{3}$ the bank offers contract $C_{2}$ with a low profit-sharing agent ratio $\left(\rho_{2}\right)$ to both types of agents, which both of whom accept.

When using another $p$ in calculating the payoff, we arrived at the same result; i.e. $\left(C_{2^{\prime}} A c^{E} A c^{\urcorner E}\right)$ is a Bayesian Nash equilibrium.

From the results, we can conclude that $\left(C_{2^{\prime}} A c^{E} A c^{\urcorner E}\right)$ is a Bayesian Nash equilibrium in our non-social bank PLS contract model example.

In the model for non-social banks, the bank only offers $C_{2}$ with a low profitsharing agent ratio $\left(\rho_{2}\right)$ to the agents, and on the contrary never offers $C_{1}$ with a high profit-sharing agent ratio $\left(\rho_{1}\right)$. The non-efficient agent accepts contracts that are not risky, and it is also possible for the efficient agent to accept these. On the other hand, they are certainly not profitable for efficient agents, who should have access to better contracts with a high profit-sharing agent $\left(\rho_{1}\right)$, which will increase the income of both the agent and the bank.

\section{Example of the Social Bank PLS Contract Model}

For an example of the social bank PLS contract model, we used the social payoff formula in equation (27). We present all the agent and bank payoffs with complete information in Table 9.

Table 9.

Bank and Agent Payoffs with Complete Information in the Social Bank Contract PLS Model Example

\begin{tabular}{lcclcc}
\hline$(E)$ & $A c$ & $\boldsymbol{R} \boldsymbol{c}$ & $(\neg E)$ & $A c$ & $\boldsymbol{R} \boldsymbol{c}$ \\
\hline$C_{1}$ & $3400 ; 2650$ & $1150 ; 400$ & $C_{1}$ & $800 ; 1987.5$ & $950 ; 200$ \\
$C_{2}$ & $2900 ; 1462.5$ & $900 ; 400$ & $C_{2}$ & $1800 ; 1300$ & $700 ; 200$ \\
\hline
\end{tabular}

We sought to find the Bayesian Nash equilibriums. We first calculated the expected payoff from each strategy. We know that $p$ is the probability that the agent is efficient, while 1- $p$ is the probability that the agent is non-efficient. We used the formulas in section 3.2 to calculate the expected payoffs and present all these for each strategy in Table 10. 
Table 10.

Expected Bank and the Agent Payoffs in the Social Bank Bayesian Games Model

\begin{tabular}{ccccc}
\hline & $\boldsymbol{A} \boldsymbol{c}^{E} \boldsymbol{A c ^ { - E }}$ & $\boldsymbol{A c ^ { E }} \boldsymbol{R} \boldsymbol{e}^{-E}$ & $\boldsymbol{R} \boldsymbol{e}^{E} \boldsymbol{A c ^ { - E }}$ & $\boldsymbol{R} \boldsymbol{e}^{E} \boldsymbol{R} \boldsymbol{e}^{-E}$ \\
\hline$C_{1}$ & $2600 p+800 ;$ & $2450 p+950 ;$ & $350 p+800 ;$ & $200 p+950 ;$ \\
& $662.5 p+1987.5$ & $2450 p+200$ & $-1587.5 p+1987.5$ & $200 p+200$ \\
$C_{2}$ & $1100 p+1800 ;$ & $2200 p+700 ;$ & $-900 p+1800 ;$ & $200 p+700 ;$ \\
\hline
\end{tabular}

Similar to the non-social bank case, to determine $p$ we compared the utility of the bank in different contracts (for all agent strategies) and compared the utility of the agent in terms of different agent strategies (for all bank strategies). As an example, we compared $u_{A}{ }^{E}\left(C_{1}, A c^{E} A c^{-E}\right)$ and $u_{A}{ }^{-E}\left(C_{2^{\prime}} A c^{E} A c^{\urcorner E}\right), 2600 \mathrm{p}+800 \geq 1100 p+1800$ or $2600 p+800 \leq 1100 p+1800$, obtaining $p \geq \frac{2}{3}$ or $p \leq \frac{2}{3}$ If we compare other bank and agent utilities, we will obtain a $p$ that satisfies $p \geq \frac{2}{3}$ or $p \leq \frac{2}{3}$, so we determine $p \geq \frac{2}{3}$ or $p \leq \frac{2}{3}$.

\section{Proposition 4:}

Based on the utilities shown in Table $10,\left(C_{2^{\prime}}, A c^{E} A c^{-E}\right)$ is a Bayesian Nash equilibrium if $p \leq \frac{2}{3}$ and $\left(C_{1}, A c^{E} A c^{-E}\right)$ is a Bayesian Nash equilibrium if $p \geq \frac{2}{3}$.

Proof:

- $\quad$ For $p \leq \frac{2}{3}$, if the agent's strategy is $A c^{E} A c^{\urcorner E}, C_{2}$ is preferable to $C_{1}$ for the bank because $1100 p+1800 \geq 2600 p+800$. If the bank's strategy is $C_{2}, A c^{E} A c^{\urcorner E}$ is preferable to the agent's other three strategies because $162.5 p+1300 \geq 1262.5 p+200$, $162.5 p+1300 \geq-900 p+1300$, and $162.5 p+1300 \geq 200 p+200$. Therefore, the strategy $\left(C_{2}, A c^{E} A c^{-E}\right)$ is a Bayesian Nash equilibrium.

- For $p \geq \frac{2}{3}$, if the agent's strategy is $A c^{E} A c^{-E}, C_{1}$ is preferable to $C_{2}$ for the bank because $2600 p+800 \geq 1100 p+1800$. If the bank's strategy is $C_{1}, A c^{E} A c^{\urcorner E}$ is preferable to the agent's other three strategies because $662.5 p+1987.5$ $\geq 2450 p+200,662.5 p+1987.5 \geq-1587.5 p+1987.5$, and $662.5 p+1987.5 \geq 200 p+200$. Therefore, strategy $\left(C_{1}, A c^{E} A c^{-E}\right)$ is a Bayesian Nash equilibrium.

Certain values of $p$ were chosen to observe the Bayesian Nash equilibrium.

For $p>\frac{2}{3}$, we chose one of the values that satisfies it, $p=0 ; 67$. We found the payoffs for all the bank and agent strategies, as shown in Table 11.

Table 11.

Bank and Agent Payoffs for $p=0.67$ in the Social Bank PLS Contract Model

\begin{tabular}{lcccc}
\hline & $\boldsymbol{A} \boldsymbol{c}^{E} \boldsymbol{A} \boldsymbol{c}^{-E}$ & $\boldsymbol{A \boldsymbol { c } ^ { E }} \boldsymbol{\boldsymbol { R } \boldsymbol { e } ^ { - E }}$ & $\boldsymbol{R} \boldsymbol{e}^{E} \boldsymbol{A} \boldsymbol{c}^{-E}$ & $\boldsymbol{R} \boldsymbol{e}^{E} \boldsymbol{R} \boldsymbol{e}^{\urcorner E}$ \\
\hline$C_{1}$ & $2542 ; 2431.4$ & $2591.5 ; 1841.5$ & $1034.5 ; 923.9$ & $1084 ; 334$ \\
$C_{2}$ & $2537 ; 1403.9$ & $2174 ; 1045.9$ & $1197 ; 697$ & $834 ; 334$ \\
\hline
\end{tabular}

Using the process of eliminating the dominant strategy, we found a Bayesian Nash equilibrium: $\left(C_{1}, A c^{E} A c^{-E}\right)$ if $p=0,67$. This means that for $p=0,67$ the bank offers contract $C_{1}$ with a high profit-sharing agent ratio $\left(\rho_{1}\right)$ to both of types of agent, both of whom accept the contract. 
Table 12 shows all the payoffs for all the bank and agent strategies if $p=\frac{2}{3}$.

Table 12.

Bank and Agent Payoffs for $\boldsymbol{p}=\frac{2}{3}$ in the Social Bank PLS Contract Model

\begin{tabular}{ccccc}
\hline & $A c^{E} \boldsymbol{A} \boldsymbol{c}^{-E}$ & $\boldsymbol{A c ^ { E }} \boldsymbol{R} \boldsymbol{e}^{-E}$ & $\boldsymbol{R} \boldsymbol{e}^{E} \boldsymbol{A} \boldsymbol{c}^{-E}$ & $\boldsymbol{R} \boldsymbol{e}^{E} \boldsymbol{R} \boldsymbol{e}^{-E}$ \\
\hline$C_{1}$ & $\mathbf{2 5 3 3 . 3 ; 2 4 2 9 . 2}$ & $2583.3 ; 1833.3$ & $1033.3 ; 929.2$ & $1083.3 ; 333.3$ \\
$C_{2}$ & $\mathbf{2 5 3 3 . 3 ; 1 4 0 8 . 3}$ & $2166.7 ; 1041.7$ & $1200 ; 700$ & $833.3 ; 333.3$ \\
\hline
\end{tabular}

For $p=\frac{2}{3}$, we can easily verify the payoffs in Table 10 and that $\left(C_{1}, A c^{E} A c^{-E}\right)$ and $\left(C_{2}, A c^{E} A c^{-E}\right)$ are Bayesian Nash equilibriums. This means that there are two possibilities for a bank to offer a contract to an agent, namely contract $C_{1}$ with a high profit-sharing agent ratio $\left(\rho_{1}\right)$ to both types of agents, who both accept the contract, or contract $C_{2}$ with a low profit- sharing agent ratio $\left(\rho_{2}\right)$ to both types, who also accept the contract.

Finally, we chose $p=\frac{1}{3}$, which satisfies $p<\frac{2}{3}$. All the payoffs of all the bank and agent strategies can be seen in Table 13.

Table 13.

Bank and Agent Payoffs for $p=\frac{1}{3}$ in the Social Bank PLS Contract Model

\begin{tabular}{ccccc}
\hline & $\boldsymbol{A} \boldsymbol{c}^{E} \boldsymbol{A} \boldsymbol{c}^{-E}$ & $\boldsymbol{A} \boldsymbol{c}^{E} \boldsymbol{R} \boldsymbol{e}^{-E}$ & $\boldsymbol{R} \boldsymbol{e}^{E} \boldsymbol{A} \boldsymbol{c}^{-E}$ & $\boldsymbol{R} \boldsymbol{e}^{E} \boldsymbol{R} \boldsymbol{e}^{-E}$ \\
\hline$C_{1}$ & $1667.7 ; 2208.3$ & $1766.7 ; 1016.7$ & $916.7 ; 1458.3$ & $1016.7 ; 266.7$ \\
$C_{2}$ & $2166.7 ; 1354.2$ & $1433.3 ; 620.8$ & $1500 ; 1000$ & $766.7 ; 266.7$ \\
\hline
\end{tabular}

For $p=\frac{1}{3}$, we have a Bayesian Nash equilibrium, $\left(C_{2^{\prime}} A c^{E} A c^{-E}\right)$ This means that for this probability, the bank only offers contract $C_{2}$ with a low profit-sharing agent ratio $\left(\rho_{2}\right)$ to both types of agents, who both accept it.

From the results presented in Tables 11, 12, and 13, we can conclude that:

- if $p \geq \frac{2}{3}\left(C_{1}, A c^{E} A c^{-E}\right)$ is a Bayesian Nash equilibrium.

- $\quad$ if $p \leq \frac{2}{3}\left(C_{2^{\prime}} A c^{E} A c^{-E}\right)$ is a Bayesian Nash equilibrium.

\section{Comparison of the game Nash equilibriums}

From the results obtained, we compared the Nash equilibrium with the game with complete information and with incomplete information, as shown in Tables 14 and 15 , respectively. 
Table 14.

Comparison of the Nash Equilibrium in the Complete Information Game for the Non-Social and Social Banks

\begin{tabular}{lcc}
\hline & $\begin{array}{c}\text { Bayesian Nash equilibrium } \\
\text { Efficient agent }\end{array}$ & $\begin{array}{c}\text { Bayesian Nash equilibrium } \\
\text { Non-efficient agent }\end{array}$ \\
\hline Non-social bank & $\left(C_{1}, A c^{E}\right)$ & $\left(C_{1}, R e^{-E}\right)$ \\
Social bank & $\left(C_{2}, A c^{E}\right)$ & $\left(C_{2}, A c^{-E}\right)$ \\
\hline
\end{tabular}

Table 15.

Comparison of the Nash Equilibrium in the Incomplete Information Game for the Non-Social and Social Banks

\begin{tabular}{lcc}
\hline & $\begin{array}{c}\text { Probability of } \\
\text { efficient agent }\end{array}$ & Bayesian Nash equilibrium \\
\hline Non-social bank & $p \in[0,1]$ & $\left(C_{2^{\prime}} A c^{E} A c^{-E}\right)$ \\
\hline \multirow{2}{*}{ Social bank } & $p \geq \frac{2}{3}$ & $\left(C_{1^{\prime}} A c^{E} A c^{-E}\right)$ \\
\cline { 2 - 3 } & $p \leq \frac{2}{3}$ & $\left(C_{2^{\prime}} A c^{E} A c^{-E}\right)$ \\
\hline
\end{tabular}

\subsection{Analysis}

In the non-social bank model, the bank only offers $C_{2}$ with a low profit-sharing agent ratio $\left(\rho_{2}\right)$ to the agents, but would never offers $C_{1}$ with a high profit-sharing agent ratio $\left(\rho_{1}\right)$ The non-efficient agent accepts the contract that is not risky, and it is also possible for the efficient agent to accept it. On the other hand, this is certainly not profitable for the efficient agent, who should have access to a contract with a higher profit-sharing agent ratio $\left(\rho_{1}\right)$. Adverse selection occurs if the efficient agent accepts contract $C_{2}$.

Based on our example of the social bank model, that if $p \geq \frac{2}{3^{\prime}}\left(C_{1}, A c^{E} A c^{\urcorner E}\right)$ is a Bayesian Nash equilibrium. This means that the efficient agent can access contract $C_{1}$ with a high profit-sharing agent ratio $\left(\rho_{1}\right)$, with which is more profitable for the agent, in contrast to the example from the non-social bank model. In this case, the non-efficient agent can also accept contract $C_{1}$ but which puts them at risk. In this case, there is an opportunity for adverse selection to occur, but the probability is low because $p \geq \frac{2}{3}$.

For $p \leq \frac{2}{3^{\prime}}$, as in the example of the social bank model, $\left(C_{2^{\prime}} A c^{E} A c^{\urcorner E}\right)$ is the Bayesian Nash equilibrium. This means that both types of agents can access contract $C_{2}$ with a low profit-sharing agent ratio $\left(\rho_{2}\right)$, which is not risky, but neither is it profitable for the efficient agent. The probability of non-efficient agents accepting contract $C_{2}$ is high because $p \leq \frac{2}{3}$.

To avoid or reduce adverse selection, the bank only offers contract $C_{1}$ with a high profit sharing- agent ratio $\left(\rho_{1}\right)$ to the efficient agent if the bank deems that the agent is highly likely to be efficient; on the other hand, it only offers contract $C_{2}$ with a low profit-sharing agent ratio $\left(\rho_{2}\right)$ to the non-efficient agent if the bank considers that there is high probability that the agent is non-efficient. These results confirm the theory of Stiglitz (1981). The probability of success of the efficient 
agent is higher than that of the non-efficient agent, so the bank offers the contract with a high profit-sharing agent ratio to the efficient agent, and offers that with a low profit-sharing agent ratio to the non-efficient agent.

It be seen how Harsanyi's (1967) approach (Bayesian game) allows a bank (social utility) to choose one or another contract by substituting a belief in $p$ for information on the efficiency of a particular agent.

\section{CONCLUSION AND RECOMMENDATIONS}

\subsection{Conclusion}

We presented a Bayesian game model for PLS (especially mudarabah) contracts in a non-social and social bank. In our model, we assumed that there were two types of agent (efficient and non-efficient) that were offered a PLS contract. Islamic banks will determine the type of agent with a certain level of probability. The model can be considered as a solution to reduce adverse selection in PLS contracts. We can determine the Bayesian Nash equilibrium in the game, which is considered to be a solution to reducing adverse selection. We have shown that for the non-social bank, the bank only offers the less risky contract with a low profit-sharing ratio to all types of agent. In the case of the social bank, if it considers with high probability that the agent is efficient, then it offers an interesting but risky contract with a high profit-sharing ratio; on the other hand, if it deems with high probability that the agent is non-efficient, then the bank offers a less risky contract with a low profitsharing ratio. These results could be considered by banks when taking decisions on offering contracts to reduce adverse selection.

\subsection{Recommendations}

For further research, we propose a repeated game, which takes place after the contract is first approved (within the duration of the contract). In this, the agent's strategy is whether to repay the loan or not, while the bank's strategy is whether or not to renew the contract.

Practitioners could consider our research results when selecting a bank to which to apply for a PLS contract and also to decide whether to accept or reject the contract.

Regulators could also consider our model and research results when offering PLS contracts. In deciding to offer a PLS contract, they need to consider the probability of the type of agent, the probability of success of the contract, and the profit-sharing ratio. 


\section{REFERENCES}

Ajmi, H., Aziz H. A., Kassim S., \& Mansour W. (2019). Adverse selection analysis for profit and loss sharing contracts. International Journal of Islamic and Middle Eastern Finance and Management, 12(4), 532-552.

Akerlof, G. A. (1970). The Market for "Lemons": Quality uncertainty and the market mechanism. The Quarterly Journal of Economics, 84(3), 488-500.

Benedikter, R. (2011). European answers to the financial crisis: Social banking and social finance. Spice Stanford : Spring.

Causse-Broquet, G. (2009). La finance islamique [Islamic finance]. Paris : Revue Banque ed.

Fakir, A. E., \& Tkiouat, M. (2016). Single or menu contracting: A game theory application of the Hersanyi model to mudaraba financing. International Journal of Economics and Financial Issues, 6(1), 221-230.

Fudenberg, D., \& Tirole, J. (1991). Game theory. London: The MIT Press.

Gait, A. H., \& Worthington, A. C., (2009). A primer on Islamic finance: Definitions, Sources, Principles and Methods (Working Paper 09). Griffith Business School.

Harsanyi, J. C. (1967). Games with incomplete information played by "Bayesian" players, I-III. Management Science, 14(3), 159-182.

Hayes, A. (September 2020). Adverse selection. Retrieved 1 September 2020 from https://www.investopedia.com/terms/a/adverseselection.asp.

Jouaber, K., \& Mehri M. (2017). A theory of profit-sharing ratio under adverse selection: The case of Islamic venture capital (Working Paper). HAL archives-ouvertes.

Kamarudin, W. N. W., \& Ismail, A. G. (2013). Profit sharing and loss bearing in financial intermediation theory. Journal of Investment Management and Financial Innovations, 10(2), 184-192.

Koçkesen, L., \& Ok, E. A. (2007). An introduction to game theory. Course at KOC Üniversite, Istanbul, Turkey. Retrieved 5 Septembre 2020 from https://www. ku.tr.

Lessy, D., Koudjeti, F., Diener M., \& Diener F. (2019). A Markov chain model for Islamic micro-financing. Journal of Islamic Monetary Economics and Finance, 5(4), 763-784.

Ouidad, Y. (2013). Does PLS financing solve asymmetric information problems? Journal of Islamic Economics, Banking and Finance, 9(3), 13-26.

Sapuan, N. M. (2016). An evaluation of mudarabah contract: A viewpoint from classical and contemporary islamics scholars. Procedia Economics and Finance, 35(2016), 349-358.

Shaikh, S. A. (2011). A critical analysis of Mudarabah \& a new approach to equity financing in Islamic finance. Journal of Islamic Banking $\mathcal{E}$ Finance, 28(3), 1-10.

Shapiro, D. A. (2015). Microfinance and dynamic incentives. Journal of Development Economics, 115(July 2015), 73-84.

Stiglitz, J. E., \& Weiss, A. (1981). Credit rationing in markets with imperfect information. The American Economic Review, 71(3), 393-410.

Tag El-Din, S. I. (2008). Income ratio, risk-sharing, and the optimality of mudarabah. Journal of King Abdulazis University: Islamic Economics, 21(2), 37-59.

Weber, O. (2014). Social banking: Concept, definitions and practice. Global Social Policy, 14(2), 265-281. 
This page is intentionally left blank 